Article

\title{
Rethinking daily movement behaviours of children with autism spectrum disorder: meeting the 24-hour movement guidelines
}

Sean Healy ${ }^{1 *}$, Freda Patterson ${ }^{1}$, Edward Williams ${ }^{1}$, Alicia J. Lozano ${ }^{2}$, Alexandra L. Hanlon ${ }^{2}$, and Iva Obrusnikova ${ }^{1}$

Received: 21 ${ }^{\text {st }}$ August 2018; Accepted: $12^{\text {th }}$ March 2020; Published: $24^{\text {th }}$ June 2020

\begin{abstract}
In an effort to promote optimal health in all children, 24-hour movement guidelines that provide specific recommendations for physical activity, screen-time, and sleep have been developed ( $\geq 1$ hour of physical activity, $\leq 2$ hours of screen-time, 9-11 hours of sleep). Children who meet the recommendations for these health behaviours are less likely to be obese than those who do not meet them. This study compared the degree to which children with autism spectrum disorder (ASD) and typically developing (TD) children met the newly developed 24-hour movement guidelines. A propensity-score matched sample of 72 children (36 children with ASD, 36 TD children) from the "Growing Up in Ireland" study was included in the analysis. Based on parents' completion of time-use diaries, fewer children with ASD, compared to TD children, met the recommendations for screentime (58.3\% vs. $80.6 \%, \mathrm{p}=0.07, \mathrm{~V}=0.24)$ and physical activity $(41.7 \%$ vs. $69.4 \%$, $\mathrm{p}=0.03, \mathrm{~V}=0.28$ ). Children with ASD were most likely to meet two guidelines (44.4\%), whereas TD children most commonly met all three guidelines (55.6\%). The findings highlight the breadth of health behaviours that require intervention among children with ASD. The current study suggests that examining the movement behaviours that constitute a 24-hour period for children with ASD may be useful to inform interventions to reduce their risk for sub-optimal health.
\end{abstract}

Keywords: Physical activity; Screen-time; Sleep; Autistic; exercise; sedentary behaviour; health; overweight; obesity

\section{Introduction}

Children with autism spectrum disorder (ASD) are up to twice as likely to be obese compared to their typically developing (TD) peers (Zheng et al., 2017) and have disproportionately higher rates of obesity-related conditions, including Type II diabetes, hypertension, and hyperlipidemia (Shedlock et al., 2016). In an effort to prevent and combat these cardiometabolic conditions, researchers have examined modifiable, behavioural determinants of obesity among children with ASD, including physical activity, sedentary behaviours, and sleep. Compared to their TD peers, data shows children with ASD to have lower levels of physical activity (Ayvazoglu, Kozub, Butera, \& Murray, 2015; Dreyer Gillette et al., 2015; McCoy, Jakicic, \& Gibbs, 2016; Pan et al., 2016; Tyler, MacDonald, \& Menear, 2014), higher levels of sedentary behaviour (Macmullin, Lunsky, \& Weiss, 2016; Must, Phillips, Curtin, \& Bandini, 2015; Orsmond \& Kuo, 2011), and poorer sleep health (Liu, Hubbard, Fabes, \& Adam, 2006; Reynolds \& Malow, 2011). 
Traditionally, among children with and without ASD, the health behaviours of physical activity, sedentary behaviour, and sleep have been largely viewed as independent determinants of health, and patterns of these behaviours have been studied in isolation. Now, researchers are increasingly recognizing the multi-etiological nature of health outcomes, such as obesity, and acknowledge that the proportion of time spent in each of these movement behaviours across the 24-hour period collectively determines the incidence and progression of disease, including obesity (Pedišić, Dumuid, \& Olds, 2017). This perspective has led to the development of 24-hour movement guidelines that provide specific recommendations for physical activity, screen-time (representing sedentary behaviour), and sleep (Tremblay et al., 2016). The guidelines recommend that, across a 24hour period, all children should engage in at least one hour of moderate-vigorous physical activity, no more than 2 hours of screen-time, and 9 to 11 hours of sleep (or 8 to 10 for children aged 14 or older) (Tremblay et al., 2016). Extensive data support the validity of the 24-hour movement guidelines for TD children. For example, children aged 9-11 years from 12 countries $(n=6128)$ who met the 24 -hour movement guidelines were $72 \%$ less likely to be obese than those who do not meet the guidelines (Roman-Viñas et al., 2016). Similarly, among 4,157 children aged 6 to 17 years, meeting none or some recommendations was associated with a higher BMI and lower aerobic fitness compared to meeting all three 24hour movement recommendations (Carson, Chaput, Janssen, \& Tremblay, 2017).

Given that the 24-hour movement guidelines provide an innovative framework with which to monitor, evaluate, and guide health promotion programming for TD children, it is critical to determine if this framework has comparable utility for children with ASD. To begin to address this knowledge gap, the purpose of this study is to compare the degree to which children with ASD and a propensity-matched sample of TD children met the 24-hour movement guidelines pertaining to their physical activity, screen-time, and sleep.

\section{Materials and Methods}

\section{Data source and subjects}

Data for the current study were obtained from the first wave of the "Growing Up in Ireland" (GUI) cohort study (Williams et al., 2009). The overall purpose of the study was to examine physical, behavioural, psychological, environmental, and cognitive outcomes of a nationally representative sample $(N=8500)$ of 9-year-old children living in Ireland. A twostage cluster-based sampling process was used with (1) a representative sample of primary schools (response rate: $82 \%$ ) being the primary sampling unit, and (2) 9-year-old children, randomly generated from within those schools, being the secondary sampling unit (response rate: $52 \%$ at the family level). Detailed information packs and consent forms were issued to all potential participating families, via their school. These documents described the type of information that would be gathered, what would be involved for participants, the longitudinal nature of the study, and details about the researchers and funding bodies. All participants, including parents and children, were informed of the voluntary nature of the study and of their right to refuse to answer any questions that they did not wish to answer. The information packs for teachers, parents, and children can be viewed in appendices A and B of the GUI study technical report (Murray et al., 2011). Interested parents/guardians were asked to return the completed consent forms to the school where they were collected by the study team. Signed consent was obtained from a parent/guardian and the study children before any data were collected (Murray et al., 2011). After consent was received, a member of the study team introduced him/herself to the participating family via a letter of introduction and a phone call. A trained GUI interviewer then visited the families' homes and administered the study's questionnaires to the child and their parent. In addition, the 
interviewer measured the child's height, to the nearest millimeter using a Leicester portable height stick, and weight, to the nearest 0.5 kilogram using a SECA 761 medically approved flat mechanical scale. Data collection occurred during the school year from September 2007 to June 2008. The Research Boards' Research Ethics Committee granted ethical approval for data collection. For more information on the GUI study design, instrumentation, and procedures please see the GUI study technical report (Murray et al., 2011).

The current study included children in the GUI data set that were identified as having an ASD diagnosis and a comparison, propensity-matched sample of children who didn't have a diagnosis of ASD. The children were classified as having a diagnosis of ASD if their primary guardian (1) responded 'yes' to the question 'Do you think [Study Child] has a specific learning difficulty, communication or co-ordination disorder?', (2) identified the nature of the difficultly or disorder as 'autism', and (3) indicated their child was 'diagnosed by a professional'. Propensity score matching (described in statistical analysis) resulted in an equally matched sample of 72 children (36 children with ASD, 36 TD children). In the matched sample, all absolute standardized mean differences (ASMD) estimates were o, indicating the groups were perfectly matched on all demographic characteristics.

Data for the current study was derived from parents' completion of a time-use diary. The structure, format, and implementation of the time-use diary used in the GUI study is similar to that used in previous national data collection studies (Gray \& Sanson, 2005; Mcginnity, Russell, Williams, \& Blackwell, 2005). In the GUI study, with the help of their child, parents recorded their child's activity using 23 pre-defined activity categories for every fifteen minutes of a day from 6am to 12 midnight. Parents could choose a primary and secondary activity per a time slot (i.e. the child may be reported to be 'watching TV' as their primary activity and eating as their secondary activity). Time-use diaries are considered to be a reliable and valid tool for representing time-use among children, demonstrating high correlation (.7 to .8) with direct observation technique (Anderson, Field, Collins, Lorch, \& Nathan, 1985; Juster \& Stafford, 1985). Moreover, they have been previously used for measuring time spent by children in screen-time activities, physical activity, and sleep (Hofferth \& Sandberg, 2001; Vandewater, Bickham, \& Lee, 2006), including for assessing discretionary time-use among children with ASD (Orsmond \& Kuo, 2011).

\section{Measures}

\section{Outcome variable: time-use data and movement behaviours}

Meeting the 24-hour movement guidelines ( $\geq 1$ hour of MVPA, $\leq 2$ hours of screen-time, 9-11 hours of sleep) was assessed based on parents' completion of a time-use diary. The structure, format, and implementation of the time-use diary used in the GUI study is similar to that used in previous national data collection studies (Gray \& Sanson, 2005; Mcginnity, Russell, Williams, \& Blackwell, 2005). In the GUI study, with the help of their child, parents recorded their child's activity using 23 pre-defined activity categories for every fifteen minutes of a day from 6 am to 12 midnight. Parents could choose a primary and secondary activity per a time slot (i.e. the child may be reported to be 'watching TV' as their primary activity and eating as their secondary activity). Time-use diaries are considered to be a reliable and valid tool for representing time-use among children, demonstrating high correlation (.7 to .8) with direct observation technique (Anderson, Field, Collins, Lorch, \& Nathan, 1985; Juster \& Stafford, 1985), and have being previously used for measuring time spent by children in screen-time activities, physical activity, and sleep (Hofferth \& Sandberg, 2001; Vandewater, Bickham, \& Lee, 2006), including for assessing discretionary time-use among children with ASD (Orsmond \& Kuo, 2011). 
Time spent in physical activity was defined as 'physical play, exercise, and sport'. Children who participated in physical activity for $\geq 1$ hour were deemed to be meeting the daily physical activity guidelines, and those who participated in $<1$ hour did not. Screentime was represented across three activity categories: Online leisure/gaming (computer, internet, PlayStation), online social activity (email, texting, contacting friends), and video entertainment (TV, DVDs). In addition, if any of these screen-based activities were listed as the second activity and the first activity was resting or eating, they were still defined as screen-time. Children who were reported to engage in screen-time for $\leq 2$ hours were deemed to meet the screen-time guidelines, and those who reported $>2$ hours of screentime did not. Time spent sleeping was represented by the difference between time of waking and time of sleeping. Children who were reported to have a total of 9 to 11 hours of sleep were deemed to have met daily sleep guidelines, and those who reported $<9$ hours or $>11$ hours of sleep did not.

\section{Covariates}

Four factors associated with movement behaviours were included in the analysis, including (1) sex of the child (boy/girl), (2) maternal completion of college education (coded as yes/no), (3) primary caregiver body mass index (BMI) derived from self-reported height and weight, and categorized as non-overweight and overweight/obese, and (4) a diet quality score. The diet quality score was derived from previous research using the GUI data (Keane et al., 2016; Perry et al., 2015) and was calculated from responses on the food frequency questionnaire that was adapted from the Sallis Amherst questionnaire (Sallis, Taylor, Dowda, Freedson, \& Pate, 2002). For eating of healthy items, a value of o was assigned for 'not eaten at all', 1 for 'eaten once' and 2 for 'eaten more than once'. Unhealthy items were assigned a value of $\mathbf{- 2}$ for 'eaten more than once', $-\mathbf{1}$ for 'eaten once' and o for 'not eaten at all'. This scoring system resulted in a continuous diet quality score ranging from -5 to 25 , whereby a higher quality score indicates more consumption of healthy foods. Completion of the time-use diary during the week (Monday-Friday) versus during the weekend (SaturdaySunday) was also included as a covariate due to preliminary analyses revealing significant differences in meeting the screen-time and physical activity guidelines based on time of diary completion.

\section{Statistical analysis}

Descriptive statistics were used to characterize the sample. Continuous variables were described using means and standard deviations, categorical variables as frequencies and percentages. Propensity score matching was used to determine if meeting 24-hour movement guidelines pertaining to physical activity, screen-time, and sleep differed in children with ASD and TD children. Propensity score matching simulates randomization in observational data by making two groups (children with ASD and TD children, in this study) as comparable as possible with respect to relevant confounding variables. Several steps were taken to match children with ASD and TD children on a propensity score so that differences in meeting the 24-hour movement guidelines could be examined. First, a logistic regression model was used to estimate a propensity score using variables known to be associated with movement behaviours (Sterdt, Liersch, \& Walter, 2014). These variables included child sex, maternal education, categorized primary caregiver BMI, dietary quality score, and time of diary completion. Second, the propensity scores from the logistic regression model were used to match each child with ASD to a TD child with the closest propensity score on a ratio of 1:1 using a nearest neighbor approach with no replacements. Absolute standardized mean differences (ASMDs) were used to evaluate the balance for individual covariates, where an ASMD below 0.20 is desirable for all variables (Cohen, 1988). Third, the association between 
meeting the 24-hour movement guidelines and ASD status within the matched sample was analyzed using Fisher's exact tests.

Propensity score matching was conducted using the MatchIt package in R, which required no missing values in the data before matching (Ho, Imai, King, \& Stuart, 2011). Missingness was no more than $3 \%$ of the final sample for all matching variables. In order to deal with missing entries, the mode was replaced for missing categorical variables and the mean for missing continuous variables prior to matching (Little \& Rubin, 2002). All other analyses were conducted using SAS Version 9.4 (SAS Institute Inc., Cary, NC). Significance was taken at the 0.05 level and effect sizes based on Cohen's d (small: 0.20, medium: 0.50, large: >0.80) and Cramer's V (small: 0.10-0.29, medium: 0.30-0.50, large: >0.50) were provided for continuous and categorical variables, respectively. Given that there were three dependent variables, we did not adjust for multiplicity, but rather interpreted our findings within the context of consistency and clinically meaningful results.

\section{Results}

Demographics of both groups were identical due to propensity score matching. The groups were predominantly male $(88.9 \%, n=32)$, and the majority of participants did not have higher education $(75 \%, n=27)$. Fifty percent $(n=16)$ of caregivers in both groups had overweight/obesity. In both groups the diaries were completed on a weekday for the majority of participants $(80.6 \%, n=29)$. Both groups had a diet quality score of $8.9(S D=4.7)$. Children with ASD were more likely to have overweight or obesity $(33.3 \%, n=12)$ compared to children with TD $(16.7 \%, n=6)$.

Table 1 displays the time spent in movement behaviours in the matched sample. There was a statistically significant difference in time spent in physical activity between the groups, with children with ASD reporting less time in physical activity than TD children ( $M=0.9$ vs. $\mathrm{M}=1.6$ hours, $\mathrm{p}=.047, \mathrm{~d}=.48$ ). Parents reported similar time spent sleeping for both children with $\operatorname{ASD}(\mathrm{M}=10.4$ hours; $\mathrm{SD}=0.8)$ and TD children $(\mathrm{M}=10.6$ hours; $\mathrm{SD}=1.0)(\mathrm{p}=.37, \mathrm{~d}=.22)$. On average, children with ASD spent 1.9 hours $(\mathrm{SD}=1.4)$ engaged in screen-time, compared to 1.6 hours $(\mathrm{SD}=1.1)$ among the TD children $(\mathrm{p}=.19, \mathrm{~d}=.24)$. Mean Body Mass Index (BMI) was $18.8(\mathrm{SD}=4.2)$ for children with $\mathrm{ASD}$ and $17.3(\mathrm{SD}=2.9)$ for TD children $(\mathrm{p}=0.08$, $\mathrm{d}=0.42)$.

Table 1 shows the prevalence rates of meeting 24-hour movement guidelines for the propensity-matched children with ASD and TD children. There were statistically significant differences in meeting recommendations for physical activity between the groups. Specifically, children with ASD were less likely to meet the physical activity recommendations ( $41.7 \%$ vs. $69.4 \%, \mathrm{p}=0.03, \mathrm{~V}=0.28$ ) as compared to TD children. Children with ASD were also less likely to meet screen-time recommendations (58.3\% vs. 80.6\%, $\mathrm{p}=.07, \mathrm{~V}=.24$ ) compared to TD children, although not statistically significant. Both groups showed similar rates of meeting sleep recommendations, with $77.8 \%(\mathrm{n}=28)$ of children with ASD and $83.3 \%(n=30)$ of TD children meeting the sleep guidelines $(p=.77, V=0.07)$. Significant differences in the total number of 24-hour movement guidelines met were found between the groups $(\mathrm{p}<.001, \mathrm{~V}=.48)$. Children with ASD were most likely to meet two guidelines $(44.4 \%, n=16)$ compared to the TD children who most commonly met all three guidelines $(55.6 \%, \mathrm{n}=20)$. Additionally, children with ASD were significantly less likely to meet all three guidelines compared to TD children (16.7\% vs. $55.6 \%, \mathrm{p}<.001, \mathrm{~V}=.40$ ). 
Table 1 Time in Movement Behaviours and Prevalence Rates of Meeting 24-Hour Guidelines for Children with ASD and TD Children in the Matched Sample $(N=72)$

\begin{tabular}{|c|c|c|c|c|}
\hline Variable & $\begin{array}{l}\text { Children with } \\
\text { ASD }(N=36)\end{array}$ & $\begin{array}{l}\text { TD Children } \\
(\mathrm{N}=36)\end{array}$ & $\mathrm{p}^{*}$ & $\begin{array}{l}\text { Effect } \\
\text { Size** }\end{array}$ \\
\hline Physical Activity (hours; Mean, SD) & $0.9(1.2)$ & $1.6(1.7)$ & .047 & .48 \\
\hline Meets PA Recommendations (N; \%) & & & .03 & .28 \\
\hline Yes ( $\geq 1$ hour) & $15(41.7 \%)$ & $25(69.4 \%)$ & & \\
\hline No $(<1$ hour $)$ & $21(58.3 \%)$ & $11(30.6 \%)$ & & \\
\hline Screen-time (hours; Mean, SD) & $1.9(1.4)$ & $1.6(1.1)$ & .19 & .24 \\
\hline Meets Screen-time Recommendations (N; \%) & & & .07 & .24 \\
\hline Yes ( $\leq 2$ hours) & $21(58.3 \%)$ & $29(80.6 \%)$ & & \\
\hline No (> 2 hours) & $15(41.7 \%)$ & $7(19.4 \%)$ & & \\
\hline Sleep (hours; Mean, SD) & $10.4(0.8)$ & $10.6(1.0)$ & .37 & .22 \\
\hline Meets Sleep Recommendations (N; \%) & & & .77 & .07 \\
\hline Yes (9-11 hours) & $28(77.8 \%)$ & $30(83.3 \%)$ & & \\
\hline No $(<9$ or $>11$ hours $)$ & $8(22.2 \%)$ & $6(16.7 \%)$ & & \\
\hline Number of Recommendations Met (N; \%) & & & $<.001$ & .48 \\
\hline 0 & $0(0.0 \%)$ & $2(5.6 \%)$ & & \\
\hline 1 & $14(38.9 \%)$ & $4(11.1 \%)$ & & \\
\hline 2 & $16(44.4 \%)$ & $10(27.8 \%)$ & & \\
\hline 3 & $6(16.7 \%)$ & $20(55.6 \%)$ & & \\
\hline Meets All 3 Recommendations (N; \%) & & & $<.001$ & .40 \\
\hline Yes & $6(16.7 \%)$ & $20(55.6 \%)$ & & \\
\hline No & $30(83.3 \%)$ & $16(44.4 \%)$ & & \\
\hline
\end{tabular}

Note: Matching variables included child sex, maternal education, categorized primary caregiver BMI, time of diary completion, and diet quality score. * ${ }^{*}$-values are based on Fisher's exact tests and two-sample tests for continuous variables. **Effect sizes are based on Cramer's V (small: 0.10-0.29, medium: 0.30-0.50, large: $>0.50$ ) and Cohen's $d$ (small: 0.20, medium: 0.50, large: 0.80 ) for continuous variables.

\section{Discussion}

\section{Meeting the 24-hour movement guidelines}

Examination of an individual's daily composite behaviours, as opposed to the study of health behaviours in isolation, represents a paradigm shift in health promotion. This study examined, for the first time, adherence to the 24-hour movement guidelines among youth with ASD in Ireland. In the current study, significant differences in the prevalence of children meeting the 24-hour movement guidelines were seen between the propensitymatched groups. Among children with ASD only 16.7\% $(n=6)$ met all three guidelines compared to $55.6 \%(\mathrm{n}=20)$ of TD children. This is particularly worrisome as research reveals that meeting less than three guidelines is associated with an increased odds of obesity (Carson et al., 2017; Roman-Viñas et al., 2016), lower levels of aerobic fitness (Carson et al., 2017), and higher triglycerides and lower HDL-cholesterol (Chaput, Carson, Gray, \& Tremblay, 2014). As children with ASD are up to twice as likely to be obese and have disproportionately higher rates of obesity-related conditions compared to TD children (Shedlock et al., 2016; Zheng et al., 2017), a more comprehensive understanding of health behaviours among this population must be sought. The current study suggests that examining the movement behaviours that constitute a 24-hour period for children with ASD may be beneficial and should prompt further research area that is framed by more integrate models of health behaviour, such as the 24-hour movement model. For example, the risks associated with failing to meet multiple 24-hour movement guidelines should be examined. Moreover, the interrelatedness between movement behaviours should be explored. Barriers and facilitators that consecutively shape multiple behaviours should also be defined. Collectively, these research endeavors will inform multi-modal health interventions that aim 
to reduce health disparities experience by children with ASD by simultaneously addressing PA, SB, and/or sleep.

\section{Physical activity and sedentary behaviour}

The failure for the majority of children with ASD to meet the physical activity and screen-time guidelines converges with the trends in previous research (Pan et al., 2016; Stanish et al., 2017; Tyler et al., 2014). For example, reflecting our findings, Stanish et al. (2017) reported that children with ASD did not spend as much time engaging in moderatevigorous physical activity as their TD counterparts $(29 \mathrm{~min} /$ day vs. $50 \mathrm{~min} /$ day respectively), falling well below the $60 \mathrm{~min} /$ day physical activity guidelines (Stanish et al., 2017). However, some research, particularly with younger children, deviates from this and suggests physical activity levels during younger years are comparable between children with and without ASD (Bandini et al., 2013; Sandt \& Frey, 2005). For example, Bandini et al. (2013) reported the mean minutes of moderate-vigorous physical activity per day to be similar between children aged 3 to 11 years with ASD $(n=53)$ and TD children $(n=58)(50$ vs. 57.1 minutes, respectively). Regarding screen-time, the current study showed that children with ASD were significantly less likely to meet the screen-time guideline compared to their TD peers (58.3\% vs. 80.6\%, respectively); this finding is largely consistent with the literature (Chonchaiya, Nuntnarumit, \& Pruksananonda, 2011; Stiller \& Mößle, 2018). Children with ASD, for example, have been shown to display more sedentary behaviour on weekdays than TD children (5.2hr/day vs. $4.2 \mathrm{hr} /$ day respectively), with most of this time spent in screen-time activities (Must, Phillips, et al., 2014). These findings on physical activity and sedentary behaviour would suggest that both behaviours represent health behaviour intervention priorities in children with ASD.

\section{Sleep}

Surprisingly, children with ASD in the current study were reported to engage in sleep for a similar amount of time as their TD counterparts (10.4 versus 10.6 hours respectively). These data diverge from much of the extant literature which reports that children with ASD experience less total sleep time and sleep quality (e.g., insomnia, parasomnias, circadian rhythm sleep-wake disorders) than the TD population (Singh \& Zimmerman, 2015). For example, van der Heijden, Stoffelsen, Popma, and Swaab, (2018) reported sleep duration to be lower among children aged 6 to 12 years with ASD compared to a TD control group during weekdays ( 588 versus 628 minutes) and weekends (604 versus 636 minutes). One possible reason for this discrepancy may be that sleep duration in the GUI study was calculated based on parental reports of the child's time in bed and thus is subject to bias.

\section{Limitations and future research}

Several limitations of the current study should be noted. First, this study utilized parentreported questionnaires and diaries which may be prone to bias due to social desirability (Adamo, et al., 2009). The effect of social desirability may be minimized in the current study due to the nature of the data collection in this study, with questionnaires focusing on a broad range of topics and not solely on health behaviours, (Garcia, Healy, \& Rice, 2016). Second, the use of diaries for data collection on movement behaviours also presents limitations, despite being used previously (Hofferth \& Sandberg, 2001; Orsmond \& Kuo, 2011) and demonstrated to be a valid measure of health behaviours among TD children (Anderson et al., 1985). For example, regarding sleep, the calculation was based on time to sleep, minus time of waking. This presents a limitation as it does not account for possible waking during the night. Accelerometer-based measures of physical activity, sedentary behaviour, and sleep should be used in future research to overcome these limitations and improve our 
understanding of the 24-movement behaviours among this population, Third, this study included a relatively small sample of children with and without ASD, from Ireland. Future research should seek to examine adherence to the 24-hour movement guidelines in other countries, with larger samples of children with ASD. Furthermore, due to the current study involving secondary data analysis of a national data set, there was a dearth of information on the characteristics of the group with ASD (e.g. severity levels, comorbidities); this further limits generalizability of findings.

Fifth and finally, the time of data collection should be considered due to the changes in ASD diagnostic procedures and changes in technology use that occurred in recent years. First, as this data was gathered in 2007-2008, and participants were 9 years old, they were diagnosed between the years 1998/1999 and 2007 using the DSM-IV. Since 2013, the current DSM (DSM-5) was released (American Psychiatric Association, 2013). Research comparing ASD prevalence using DSM-IV and DSM- 5 concluded that almost all individuals with DSM-IV Autistic Disorder (98\%) and Asperger Disorder (92\%) met the new DSM-5 ASD diagnostic criteria (Kim et al., 2014). With these results in mind, we propose that research on children with ASD diagnosed prior to 2013 is still generalizable to children with ASD diagnosed post-2013. We do, however, strongly recommend that similar studies apply the 24-hour movement framework with more recent, larger samples of children with ASD. Second, the changes in technology use in recent years should be considered when interpreting the current study's findings. Although research on TD children over the past decade has shown some consistent findings in trends of health behaviours (Colley et al., 2017; Hoyos, Glozier, \& Marshall, 2015), the ever-changing technological environment's influence on health behaviours (in particular screen-time behaviours) requires up-to-date examination. Therefore, we recommend that future researchers seek to collect and explore more recent accelerometer-based data to improve our understanding of the patterns of health behaviours among children with ASD.

\section{Perspectives}

The current study extends the use of the new 24-hour movement guidelines (Tremblay et al., 2016; Roman-Viñas et al., 2016; Carson, Chaput, Janssen, \& Tremblay, 2017) to children with ASD and provides an insight into how adherence to the guidelines compares between 9-year-old children with ASD and a propensity-score matched sample of TD peers. Data demonstrated that fewer children with ASD, compared to TD children, met the recommendations for screen-time ( $58.3 \%$ vs. $80.6 \%$ ) and physical activity (41.7\% vs. $69.4 \%$ ), and children with ASD were most likely to meet two guidelines (44.4\%), whereas TD children most commonly met all three guidelines (55.6\%). The findings should prompt a more holistic study of health behaviours among children with ASD, including seeking to understand the health behaviours, or combinations thereof, most pertinent for health among children with ASD and an examination of how 24-hour movement components (i.e. PA, SB, and SD) interact with one another. Such work will help us identify the most critical target behaviours for the development of interventions to counteract the poorer health status among children with ASD.

\footnotetext{
Author affiliations:

1 Department of Behavioural Health and Nutrition, University of Delaware, DE, 19716, United States. Healys@udel.edu, fredap@udel.edu, eaw@udel.edu, obrusnik@udel.edu

2 Center for Biostatistics and Health Data Science, Department of Statistics, Virginia Tech, Roanoke, VA, 24016 19104, United States. aliciajlozano@gmail.com, al hanlon@comcast.net

* Correspondence: healys@udel.edu; Tel.: 302-831-3997
}

Author Contributions: Conceptualization, FP \& SH. Methodology; FP, AH \& AL. Formal Analysis; AH \& AL. Writing-Original Draft Preparation; SH, FP, IO, \& EW. Writing-Review \& Editing: FP \& IO.

Funding: This research received no external funding 
Conflicts of Interest: The authors declare no conflict of interest.

\section{References}

Adamo, K.B., Prince, S.A., Tricco, A.C., Connor-Gorber, S., \& Tremblay, M. (2009). A comparison of indirect versus direct measures for assessing physical activity in the pediatric population: a systematic review. International Journal of Pediatric Obesity, 4(1), 2-27. https://doi.org/10.1080/17477160802315010

American Psychiatric Association. (2013). Diagnostic and statistical manual of mental disorders (5th ed.). American Psychiatric Publishing.

Anderson, D. R., Field, D. E., Collins, P. A., Lorch, E. P., \& Nathan, J. G. (1985). Estimates of young children's time with television: a methodological comparison of parent reports with time-lapse video home observation. Child Development, 56(5), 13451357. https://doi.org/10.1111/j.1467-8624.1985.tboo202.x

Ayvazoglu, N. R., Kozub, F. M., Butera, G., \& Murray, M. J. (2015). Determinants and challenges in physical activity participation in families with children with high functioning autism spectrum disorders from a family systems perspective. Research in Developmental Disabilities, 47, 93-105. https://doi.org/10.1016/j.ridd.2015.08.015

Bandini, L. G., Gleason, J., Curtin, C., Lividini, K., Anderson, S. E., Cermak, S. A., Maslin, M., \& Must, A. (2013). Comparison of physical activity between children with autism spectrum disorders and typically developing children. Autism, 17(1), 44-54. https://doi.org/10.1177/1362361312437416

Carson, V., Chaput, J.-P., Janssen, I., \& Tremblay, M. S. (2017). Health associations with meeting new 24-hour movement guidelines for Canadian children and youth. Preventive Medicine, 95, 7-13. https://doi.org/10.1016/j.ypmed.2016.12.005

Chaput, J. P., Carson, V., Gray, C. E., \& Tremblay, M. S. (2014). Importance of all movement behaviors in a 24 hour period for overall health. International Journal of Environmental Research and Public Health, 11(12), 12575-12581. https://doi.org/10.3390/ijerph111212575

Chonchaiya, W., Nuntnarumit, P., \& Pruksananonda, C. (2011). Comparison of television viewing between children with autism spectrum disorder and controls. Acta Paediatrica, 10O(7), 1033-1037. https://doi.org/10.1111/j.1651-2227.2011.02166.x

Cohen J. (1988). Statistical power analysis for the behavioral sciences (2nd ed.). Lawrence Erlbaum Associates.

Colley, R.C., Carson, V., Garriguet, D., Janssen, I., Roberts, K.C., \& Tremblay, M.S. (2017). Physical activity of Canadian children and youth, 2007 to 2015. Statistics Canada.

Dreyer Gillette, M. L., Borner, K. B., Nadler, C. B., Poppert, K. M., Odar Stough, C., Swinburne Romine, R., \& Davis, A. M. (2015). Prevalence and health correlates of overweight and obesity in children with autism spectrum disorder. Journal of Developmental and Behavioral Pediatrics, 36(7), 489-496. https://doi.org/10.1097/DBP.0000000000000198

Garcia, J. M., Healy, S., \& Rice, D. (2016). The individual, social, and environmental correlates of physical activity and screen time in Irish children: Growing up in Ireland study. Journal of Physical Activity and Health, 13(12), 1285-1293. https://doi.org/10.1123/jpah.2015-0659.

Gray, M., \& Sanson, A. (2005). Growing up in Australia: the longitudinal study of Australian children. Retrieved from https://aifs.gov.au/sites/default/files/mg(2).pdf

Ho, D. E., Imai, K., King, G., \& Stuart, E. A. (2011). MatchIt : Nonparametric preprocessing for parametric causal inference. Journal of Statistical Software, 42(8), 1-28. https://doi.org/10.18637/jss.v042.io8

Hoyos, C., Glozier, N., \& Marshall, N.S. (2015). Recent evidence on worldwide trends on sleep duration. Current Sleep Medicine Reports, 1(4), 195-204. https://doi.org/10.1007/s40675-015-0024-X

Hofferth, S. L., \& Sandberg, J. F. (2001). How American children spend their time. Journal of Marriage and Family, 63(2), 295-308. https://doi.org/10.1111/j.17413737.2001.00295.x 
Juster, F. T., \& Stafford, F. P. (1985). The allocation of time: empirical findings, behavioral models, and problems of measurement. Journal of Economic Literature, 29(2), 471522. https://doi.org/10.2307/2727521

Keane, E., Cullinan, J., Perry, C. P., Kearney, P. M., Harrington, J. M., Perry, I. J., \& Layte, R. (2016). Dietary quality in children and the role of the local food environment. SSM Population Health, 2, 770-777. https://doi.org/10.1016/j.ssmph.2016.10.002

Kim, Y.S., Fombonne, E., Koh, Y.J., Kim, S.J., Cheon, K.A., \& Leventhal, B.L. (2014). A comparison of DSM-IV pervasive developmental disorder and DSM- 5 autism spectrum disorder prevalence in an epidemiologic sample. Journal of the American Academy of Child \& Adolescent Psychiatry, 53(5), 500-508. https://doi.org/10.1016/j.jaac.2013.12.021

Little, R., and Rubin, D. (2002). Statistical analysis with missing data [2nd ed]. John Wiley \& Sons.

Liu, X., Hubbard, J. A., Fabes, R. A., \& Adam, J. B. (2006). Sleep disturbances and correlates of children with autism spectrum disorders. Child Psychiatry and Human Development, 37(2), 179-191. https://doi.org/10.1007/s10578-006-0028-3

Macmullin, J. A., Lunsky, Y., \& Weiss, J. A. (2016). Plugged in: Electronics use in youth and young adults with autism spectrum disorder. Autism, 2O(1), 45-54. https://doi.org/10.1177/1362361314566047

McCoy, S. M., Jakicic, J. M., \& Gibbs, B. B. (2016). Comparison of obesity, physical activity, and sedentary behaviors between adolescents with autism spectrum disorders and without. Journal of Autism and Developmental Disorders, 46(7), 2317-2326. https://doi.org/10.1007/s10803-016-2762-o

Mcginnity, F., Russell, H., Williams, J., \& Blackwell, S. (2005). Time use in Ireland 2005: survey report. Dublin. Retrieved from www.esri.ie

Murray, A., McCrory, C., Thornton, M., Williams, J., Quail, A., Swords, L., \& Doyle, E. (2011). Growing up in Ireland: design, instrumentation and procedures for the child cohort (at 9 years) | ESRI - The economic and social research institute. Dublin. Retrieved from https://www.esri.ie/publications/growing-up-in-ireland-designinstrumentation-and-procedures-for-the-child-cohort-at-9-years/

Must, A., Phillips, S., Curtin, C., \& Bandini, L. G. (2015). Barriers to physical activity in children with autism spectrum disorders: relationship to physical activity and screen time. Journal of Physical Activity and Health, 12(4), 529-534. https://doi.org/10.1123/jpah.2013-0271

Orsmond, G. I., \& Kuo, H.-Y. (2011). The daily lives of adolescents with an autism spectrum disorder: discretionary time use and activity partners. Autism : The International Journal of Research and Practice, 15(5), 579-599. https://doi.org/10.1177/1362361310386503

Pan, C., Tsai, C. L., Chu, C. H., Sung, M. C., Ma, W. Y., \& Huang, C. Y. (2016). Objectively measured physical activity and health-related physical fitness in secondary schoolaged male students with autism spectrum disorders. Physical Therapy, 96(4), 511520. https://doi.org/10.2522/ptj.20140353

Pedišić, Ž., Dumuid, D., \& Olds, T. S. (2017). Integrating sleep, sedentary behaviour, and physical activity research in the emerging field of time-use epidemiology: Definitions, concepts, statistical methods, theoretical framework, and future directions. Kinesiology, 49, 252-269.

Perry, C. P., Keane, E., Layte, R., Fitzgerald, A. P., Perry, I. J., \& Harrington, J. M. (2015). The use of a dietary quality score as a predictor of childhood overweight and obesity. BMC Public Health, 15(1), 581. https://doi.org/10.1186/s12889-015-1907-y

Reynolds, A. M., \& Malow, B. A. (2011). Sleep and autism spectrum disorders. Pediatric Clinics of North America, 58(3), 685-698. https://doi.org/10.1016/j.pcl.2011.03.009

Roman-Viñas, B., Chaput, J.-P., Katzmarzyk, P. T., Fogelholm, M., Lambert, E. V, Maher, C., ... ISCOLE Research Group, for the I. R. (2016). Proportion of children meeting recommendations for 24-hour movement guidelines and associations with adiposity in a 12-country study. International Journal of Behavioral Nutrition and Physical Activity, 13(1), 123. https://doi.org/10.1186/s12966-016-0449-8 
Sallis, J. F., Taylor, W. C., Dowda, M., Freedson, P. S., \& Pate, R. R. (2002). Correlates of vigorous physical activity for children in grades 1 through 12: Comparing parentreported and objectively measured physical activity correlates of vigorous physical activity for children in grades. Pediatric Exercise Science, 14(1), 30-44. https://doi.org/10.1123/pes.14.1.30

Sandt, D.D.R., \& Frey, G.C. (2005). Comparison of physical activity levels between children with and without autistic spectrum disorders. Adapted Physical Activity Quarterly, 22(2), 146-159. https://doi.org/10.1123/apaq.22.2.146

Shedlock, K., Susi, A., Gorman, G. H., Hisle-Gorman, E., Erdie-Lalena, C. R., \& Nylund, C. M. (2016). Autism spectrum disorders and metabolic complications of obesity. Journal of Pediatrics, 178, 183-187. https://doi.org/10.1016/j.jpeds.2016.07.055

Singh, K., \& Zimmerman, A. W. (2015, June 1). Sleep in autism spectrum disorder and attention deficit hyperactivity disorder. Seminars in Pediatric Neurology, 22(2), 113125 https://doi.org/10.1016/j.spen.2015.03.006.

Stanish, H.I., Curtin, C., Must, A., Phillips, S., Maslin, M., \& Bandini, L.G. (2017). Physical activity levels, frequency, and type among adolescents with and without autism spectrum disorder. Journal of autism and developmental disorders, 47(3), 785-794. https://doi.org/10.1007/s10803-016-3001-4

Sterdt, E., Liersch, S., \& Walter, U. (2014). Correlates of physical activity of children and adolescents: A systematic review of reviews. Health Education Journal, 73(1), 72-89. https://doi.org/10.1177/0017896912469578

Stiller, A., \& Mößle, T. (2018). Media use among children and adolescents with autism spectrum disorder: A systematic review. Review Journal of Autism and Developmental Disorders, 5(3), 227-246. https://doi.org/10.1007/s40489-018-0135-7

Tremblay, M. S., Carson, V., Chaput, J.-P., Connor Gorber, S., Dinh, T., Duggan, M., ... Zehr, L. (2016). Canadian 24-hour movement guidelines for children and youth: An integration of physical activity, sedentary behaviour, and sleep. Applied Physiology, Nutrition, and Metabolism, 41(6), 311-327. https://doi.org/10.1139/apnm-2016-0151

Tyler, K., MacDonald, M., \& Menear, K. (2014). Physical activity and physical fitness of school-aged children and youth with autism spectrum disorders. Autism Research and Treatment, 2014, 1-6. https://doi.org/10.1155/2014/312163

van der Heijden, K. B., Stoffelsen, R. J., Popma, A., \& Swaab, H. (2018). Sleep, chronotype, and sleep hygiene in children with attention-deficit/hyperactivity disorder, autism spectrum disorder, and controls. European Child and Adolescent Psychiatry, 27(1), 99-111. https://doi.org/10.1007/s00787-017-1025-8

Vandewater, E. A., Bickham, D. S., \& Lee, J. H. (2006). Time well spent? Relating television use to children's free-time activities. Pediatrics, 117(2), e181-91. https://doi.org/10.1542/peds.2005-0812

Williams, J., Greene, S., Doyle, E., Harris, E., Layte, R., McCoy, S., ... Thornton, M. (2009). Growing up in Ireland. Dublin. Retrieved from www.omc.gov.ie

Zheng, Z., Zhang, L., Li, S., Zhao, F., Wang, Y., Huang, L., ... Mu, D. (2017). Association among obesity, overweight and autism spectrum disorder: A systematic review and meta-analysis. Scientific Reports, 7(1), 1-9. https://doi.org/10.1038/s41598-01712003-4

(C) 2020 by the authors. Submitted for possible open access publication under the terms and conditions of the Creative Commons Attribution (CC BY) license (http://creativecommons.org/licenses/by/4.o/). 